\title{
High hydrostatic pressure effects on arginine vasotocin levels in fish
}

\author{
Arnau Rodríguez-Illamola ${ }^{1,2, *}$, Jesús M. Míguez ${ }^{1}$, João Coimbra ${ }^{3}$, \\ Jonathan M. Wilson ${ }^{3,4}$ \\ ${ }^{1}$ Laboratory of Animal Physiology, Department of Functional Biology and Health Sciences, Faculty of Biology, \\ University of Vigo, 36310 Vigo, Spain \\ ${ }^{2}$ Laboratory of Fish Reproduction, Faculty of Fisheries and Protection of Waters, \\ South Bohemian Research Center of Aquaculture and Biodiversity of Hydrocenoses, University of South Bohemia in České \\ Budějovice, Zátiší 728/II, 38925 Vodňany, Czech Republic \\ ${ }^{3}$ Laboratory of Ecophysiology, Centro Interdisciplinar de Investigação Marinha e Ambiental (CIIMAR), \\ 4450-208 Matosinhos, Portugal
}

${ }^{4}$ Present address: Department of Biology, Wilfrid Laurier University, 75 University Ave W, Waterloo, ON N2L 3C5, Canada

\begin{abstract}
The present study investigates the response of the hormone arginine vasotocin (AVT), the non-mammalian antidiuretic hormone, to the acclimation of fish to high hydrostatic pressure $(5.1 \mathrm{MPa})$. Two fish species with different osmoregulatory strategies, the lesser spotted dogfish Scyliorhinus canicula, a marine osmoconforming chondrichthyan species adapted for migration to deep waters, and the rainbow trout Oncorhynchus mykiss, a pressuresensitive freshwater species, were selected for study. Fish were exposed to hydrostatic pressures of either 0.1 (control) or $5.1 \mathrm{MPa}$ in hydrostatic chambers for up to 2 wk at their appropriate salinities. Plasma cortisol was measured in trout, and plasma chloride, sodium and potassium were measured in both fish species. A transient high level of plasma AVT was found in dogfish and in trout after 1 and $3 \mathrm{~d}$ of exposure to high hydrostatic pressure, which returned to basal levels by $14 \mathrm{~d}$ of exposure. In contrast, pituitary AVT content was reduced after shortterm exposure in dogfish, while in trout, lower expression was found in high pressure than in control conditions, independently of exposure time. In dogfish, pituitary AVT levels recovered by $14 \mathrm{~d}$ under high hydrostatic pressure. No changes in plasma cortisol (trout) or ions (both species) were observed. These initial increases of the AVT release from the pituitary during fish acclimation to high pressure suggest that it works as a physiological short-term response to reduce water loss and equilibrate ion osmotic balance.
\end{abstract}

KEY WORDS: Fish - Acclimation - Hydrostatic pressure -Arginine vasotocin - Rainbow trout Dogfish

\section{INTRODUCTION}

Deep waters in lakes, seas and oceans differ in several physical parameters from their respective shallow depths, affecting the physiology and evolutionary patterns of fish that live or migrate there (Gibbs

\footnotetext{
*Corresponding author: arnauvigo@gmail.com
}

1997, Gaither et al. 2016, Priede 2017). In addition to very low temperatures, reduced oxygen availability and little illumination, high hydrostatic pressure is another relevant condition which fish living at depth must deal with. Hydrostatic pressure increases by approximately $0.1 \mathrm{MPa}(1 \mathrm{~atm})$ every $10 \mathrm{~m}$ of depth

( ) The authors 2020. Open Access under Creative Commons by Attribution Licence. Use, distribution and reproduction are unrestricted. Authors and original publication must be credited. 
(U.S. Navy Diving Manual. https://www.navsea.navy. mil/Portals/103/Documents/SUPSALV/Diving/US\%20 DIVING\%20MANUAL_REV7.pdf?ver=2017-01-11102354-393). Many fish species can tolerate hydrostatic pressures corresponding to depths greater than $6000 \mathrm{~m}$ (approximately $59 \mathrm{MPa}$ ) (Günther 1887), while others can migrate vertically from about $1000 \mathrm{~m}$ (approximately 9.8 MPa), as is the case of Osteichthyes, including the Atlantic bluefin tuna (Block et al. 2001), and cyclostomes, including the European eel (Righton et al. 2016), or from 600 m (approximately $5.9 \mathrm{MPa}$ ) in some chondrichthyan species, such as the blue shark (Kyne \& Simpfendorfer 2010). Meanwhile, another group of species can tolerate high hydrostatic pressure conditions even if they do not live or migrate to great depth environments (Sébert \& Theron 2001). These eurybathic species, such as the trout (Sébert \& Theron 2001), are well suited to the study of the plasticity of fish physiological mechanisms, as it relates to their response to hydrostatic pressure changes.

Exposure to high hydrostatic pressures has been shown to induce important changes in fish general physiology (Sébert 2002) and metabolism (Yancey \& Siebenaller 2015). Immediate increases in fish locomotor activity and, consequently, increases in oxygen consumption and in some metabolic rates were observed, which were followed by slow acclimations towards a new steady state to basal levels (for reviews, see also Gibbs 1997). Furthermore, in the freshwater eel, high hydrostatic pressure produces large inhibitory effects on cellular structure and decreases in cell membrane fluidity (Somero 1992, Vettier et al. 2006) as well as increases in circulating and tissue ion levels (sodium, chloride and magnesium in blood, and sodium and chloride in gills and muscles) after long-term acclimation (Simon et al. 1989, Sébert et al. 1991). These changes in tissue ion concentrations were explained as a consequence, at least in part, of passive ion entry into the cells caused by a direct inhibition of specific ion transport mechanisms during the adjustment of a new state of energetic metabolism, as a result of the concurrent acclimation to high-pressure conditions (Péqueux 2008).

Fish response mechanisms to confront the negative effects produced by high-pressure conditions have also been studied. This is the case of trimethylamine $\mathrm{N}$-oxide, which has been seen to be involved in the evolutionary adaptation of deep-sea fish, contributing to a reduction in their osmoregulatory costs at great depths by counteracting the disturbances to cellular proteins induced by high pressures (Gillet et al. 2001, Yancey et al. 2001, 2014). However, even though ion osmotic and co-solute/osmolyte pressure adaptations are of major importance for fish in hyperbaric environments, the effects of these environments in their regulatory mechanisms are not very well studied (Sébert et al. 2007, Damasceno-Oliveira et al. 2012).

Arginine vasotocin (AVT), the non-mammalian homolog of vasopressin, is a nonapeptide synthesized in the preoptic area of the hypothalamus of fish, amphibians, birds and reptiles (Acher 1996). AVT works as a neurotransmitter in brain regions that are in contact with vasotocinergic projections (Absil et al. 2002, Maruska et al. 2007) and, as a hormone, it is released into the blood from specific vasotocinergic axonal projections of the pituitary neurohypophyseal lobe (Duarte et al. 2001, Uchiyama et al. 2014, Chaube et al. 2015).

Several studies in euryhaline teleost fish species, including the rainbow trout Oncorhynchus mykiss (Kulczykowska 1997, 2007), the European flounder Platichthys flesus (Balment et al. 1993) and the gilthead seabream Sparus aurata (Sangiao-Alvarellos et al. 2006, Mancera et al. 2018), as well as in chondrichthyan species such as the bull shark Carcharhinus leucas (Anderson et al. 2006) or the banded houndshark Triakis scyllium (Hyodo et al. 2004) clearly support that AVT works as an antidiuretic signaling molecule which acts mainly in the kidney and gills through specific receptors (Martos-Sitcha et al. 2014, Lema et al. 2019). In the kidney, the hormone promotes water reabsorption and restoration by acting on specific $\mathrm{V}_{2}$-type receptors of the renal collecting ducts (Amer \& Brown 1995, McCormick \& Bradshaw 2006). In gills, it produces branchial upregulation of salt secretion mechanisms (through alteration of the cystic fibrosis transmembrane conductance regulator $\mathrm{Cl}^{-}$channel) and downregulation of salt uptake mechanisms (through modulation of the $\mathrm{Na}^{+}: \mathrm{Cl}^{-}$co-transporter 2, ncc2) (Lema et al. 2019).

Considering the role of AVT in regulation of the ion osmotic balance and the described effects of high hydrostatic pressure on ion concentrations in fish blood (Simon et al. 1989, Péqueux 2008), it is intriguing to explore how hydrostatic pressure affects the AVT system and whether the possible responses are species specific or not. For that purpose, 2 fish species with different osmoregulatory responses and with different strategies in relation to pressure acclimation were selected: the dogfish Scyliorhinus canicula (L. 1758), a marine osmoconforming chondrichthyan species adapted for migration to deep waters (Wearmouth et al. 2013), and the rainbow trout 
O. mykiss (Carrera et al. 1998), a non-anadromous, pressure-sensitive, osmoregulating Osteichthyes (Sébert \& Theron 2001).

\section{MATERIALS AND METHODS}

\subsection{Animals}

Thirty-six immature female rainbow trout Oncorhynchus mykiss of $22.60 \pm 0.48 \mathrm{~g}$ body mass (mean $\pm \mathrm{SE}$ ), obtained from the commercial hatchery A Coelho and Castro Lda, Estela, Portugal, and 36 mature dogfish Scyliorhinus canicula (mixed-sex individuals) of $614.67 \pm 24.82 \mathrm{~g}$ body mass, obtained from local fisheries bycatch, were used for the experiments. Trout were kept in aerated, filtered freshwater (dechlorinated Porto city tap water; $0.6 \%$ ) and dogfish in artificial seawater $(34 \%)$, in both cases under an artificial photoperiod regime (14 h light:10 h dark) at $14 \pm 2^{\circ} \mathrm{C}$ for $10 \mathrm{~d}$ before the beginning of the experiments. Trout were fed daily at 12:00 h with a commercial dry pellet diet (EWOS) ad libitum and dogfish with mackerel at the same time of the day. Both were food deprived for $24 \mathrm{~h}$ before the first day of the experiment that was performed during November and December. All experiments complied with the guidelines of protection for animals used for scientific purposes from European directive 2010/63/UE, and the procedures were approved by the animal care committee of the Centro Interdisciplinar de Investigação Marinha e Ambiental (CIIMAR).

\subsection{Experiments and sampling}

Fish were transferred to custom-built chambers for hydrostatic pressure control of 2001 capacity (6 individuals of the same species per chamber and sampling time) (Damasceno-Oliveira et al. 2004). Each chamber was equipped with a $1000 \mathrm{l}$ reservoir for recirculation of aerated water of the same characteristics mentioned above to maintain optimal water conditions for each species. The same artificial photoperiod was maintained (14 h light: $10 \mathrm{~h}$ dark) during the experiment. A hydrostatic pressure of $5.1 \mathrm{MPa}$ (approximately $52 \mathrm{~atm}$, which corresponds to approximately $520 \mathrm{~m}$ of depth) was established slowly (by increasing $0.25 \mathrm{MPa}$ per minute), as previously reported (Correia et al. 2012), to avoid possible stress to the fish in the chambers of the treatment group. This procedure was confirmed in a shorter assay performed previously at CIIMAR, based on the analysis of plasma cortisol levels in rainbow trout exposed for 1, 3 and $7 \mathrm{~d}$ to high hydrostatic pressure of $5.1 \mathrm{MPa}$. The respective control group was kept in an identical chamber under $0.1 \mathrm{MPa}$, corresponding to the hydrostatic pressure at the water surface (approximately $1 \mathrm{~atm})$.

Fish were sampled after 1,3 , or $14 \mathrm{~d}$ in the respective experimental condition for AVT measurements. Since only 2 chambers were available, the experiment was repeated 3 times for sampling at each time point. On the respective sampling day, after a slow decompression of the system (0.25 $\mathrm{MPa}$ per minute) in the high hydrostatic pressure chamber or directly in the control, fish were quickly removed from the chambers, always at 15:00 h, and deeply anaesthetized with MS-222 (50 $\mathrm{mg} \mathrm{l}^{-1}$ ) buffered to $\mathrm{pH} 7.4$ with sodium bicarbonate. Blood samples $(0.5 \mathrm{ml}$ in trout, $1 \mathrm{ml}$ in dogfish) were collected from the caudal vein using heparinized syringes within $30 \mathrm{~min}$ of the beginning of the decompression and centrifuged for $8 \mathrm{~min}$ at $20930 \times \mathrm{g}$, and plasma was collected and stored at $-80^{\circ} \mathrm{C}$. Subsequently, fish were sacrificed by decapitation, and the brains were extracted for pituitary collection. Tissues were removed under sterile conditions, rapidly frozen in liquid nitrogen and transferred to a $-80^{\circ} \mathrm{C}$ freezer for storage until analysis. As mentioned above, a previous experiment was done in trout for cortisol and ion analyses, with slightly different sampling days (1, 3 and 7 d) but identical exposure (high

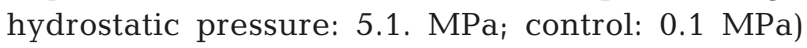
and sampling methods.

\subsection{Plasma and pituitary AVT quatification}

Circulating AVT was extracted and analyzed according to Rodríguez-Illamola et al. (2011) using gradient reversed-phase HPLC and fluorometric detection (FD). AVT quantification was preceded by solid phase extraction (SPE) of $200 \mu$ l of plasma and the subsequent derivatization of the peptide in the SPE column with 4-fluoro-7-nitro-benzofurazan (NBDF) to facilitate fluorescence detection of AVT during the HPLC analysis. The AVT-NBDF complex was separated chromatographically on a Beckman Ultrasphere ODS column $(250 \times 4.6 \mathrm{~mm}$ i.d.; $5 \mu \mathrm{m}$ particle diameter $)$, and detection was undertaken at $530 \mathrm{~nm}$ of emission with an excitation wavelength of $470 \mathrm{~nm}$ (Jasco FP2020 fluorescence detector). 
Pituitaries were individually disrupted by sonication in $100 \mu \mathrm{l}$ HPLC-grade water and centrifuged at 20930 $\times g$ for $10 \mathrm{~min}$. Then, $10 \mu \mathrm{l}$ aliquots of each sonicated sample were separated to analyze each organ's total protein content by using the bicinchoninic acid method in microplates (Smith et al. 1985). Supernatants were subsequently filtered by using centrifuge filters $(0.45 \mu \mathrm{m})$ for $20 \mathrm{~min}$ at $20930 \times g$, and the purified extract was used to quantify the AVT content, injecting the sample directly to a gradient reversedphase HPLC with FD, following previous instructions described in Rodríguez-Illamola et al. (2011). Pituitary AVT values were then normalized by total protein content.

\subsection{Plasma chloride, sodium, potassium and cortisol analyses}

Plasma sodium and potassium concentrations were analyzed by flame photometry (PFP7, Jenway), while chloride concentration was quantified by titration (Corning M925 Chloride Analyzer). Plasma cortisol of the respective samples was measured using a commercial ELISA (Neogen).

\subsection{Statistical analyses}

Data are presented as mean $\pm \mathrm{SE}$. AVT and cortisol were tested for homogeneity of variation (Levene's mean test) and normality (Shapiro-Wilks) and then a 2-way ANOVA with hydrostatic pressure and exposure time as main factors, followed by a post hoc Holm-Sidak test. Plasma monovalent ions were compared by unpaired $t$-tests. In all cases, differences were considered significant at $\mathrm{p}<0.05$. Sigma Plot v11 software was used for statistics and graphs.

\section{RESULTS}

\subsection{High hydrostatic pressure effects on circulating and pituitary AVT levels in trout}

Fig. 1 shows AVT levels in the plasma and pituitary of trout under hydrostatic pressure conditions corresponding to the surface water level (control; $0.1 \mathrm{MPa}$ ) and of trout exposed to high hydrostatic pressure conditions (treatment; 5.1 MPa). The effects of high hydrostatic pressure on circulating AVT levels were dependent on exposure time (2-way ANOVA: interaction $p=0.002)$. Circulating AVT levels were higher in fish exposed to high hydrostatic pressure at 1 and $3 \mathrm{~d}$, but by $14 \mathrm{~d}$ levels returned to basal values of control fish (Fig. 1A). In contrast, pituitary AVT levels were significantly lower in high hydrostatic pressure exposed trout than in control trout (2-way ANOVA: $F_{1,22}=$ 13.528 ; $\mathrm{p}=0.001)$ but with no effect of time (2way ANOVA: $F_{1,22}=1.177 ; \mathrm{p}=0.327$ ).

\subsection{High hydrostatic pressure effects on circulating and pituitary AVT levels in dogfish}

AVT levels in the plasma and pituitary of dogfish kept under control and high hydrostatic pressure conditions are shown in Fig. 2. Circulating AVT levels in control dogfish groups were close to 8-fold higher than those in trout, while the pituitary content was 2 times lower than that in trout.

Significant effects of high-pressure treatment (2way ANOVA: $\left.F_{1,21}=45.602 ; \mathrm{p}<0.001\right)$ and exposure time (2-way ANOVA: $F_{2,21}=12.453 ; \mathrm{p}<$ 0.001 ) as well as a significant interaction time $\times$ treatment (2-way ANOVA: $F_{2,21}=8.885 ; \mathrm{p}=0.002$ ) were observed for the circulating AVT levels in dogfish (Fig. 2A). Control fish maintained similar circulating levels during all sampling days, while fish exposed for 1 and $3 \mathrm{~d}$ to high hydrostatic pressure displayed higher circulating AVT levels than their corresponding controls $(p<0.001)$. Between $3 \mathrm{~d}$ and $14 \mathrm{~d}$ in high hydrostatic pressure, values fell to basal levels ( $p=0.539$ ).

Pituitary AVT levels in dogfish were significantly affected by hydrostatic pressure (2-way ANOVA: $\left.F_{1,22}=12.654 ; \mathrm{p}=0.002\right)$ and exposure time (2-way ANOVA: $F_{2,22}=10.268 ; \mathrm{p}<0.001$ ) (Fig. 2B), with an interaction observed between treatment and time (2-way ANOVA: $\left.F_{2,22}=8.788 ; \mathrm{p}=0.002\right)$. Control fish maintained similar pituitary AVT levels over the $14 \mathrm{~d}$, while levels decreased in dogfish exposed for 1 and $3 \mathrm{~d}$ at high hydrostatic pressure when compared with levels of the respective controls. After $14 \mathrm{~d}$, treated fish recovered pituitary AVT levels.

\subsection{High hydrostatic pressure effects on monovalent ions and cortisol plasma levels in trout and dogfish}

Dogfish in water with salinity of $34 \%$ had approximately double the concentration of chloride, sodium and potassium when compared to trout kept in 

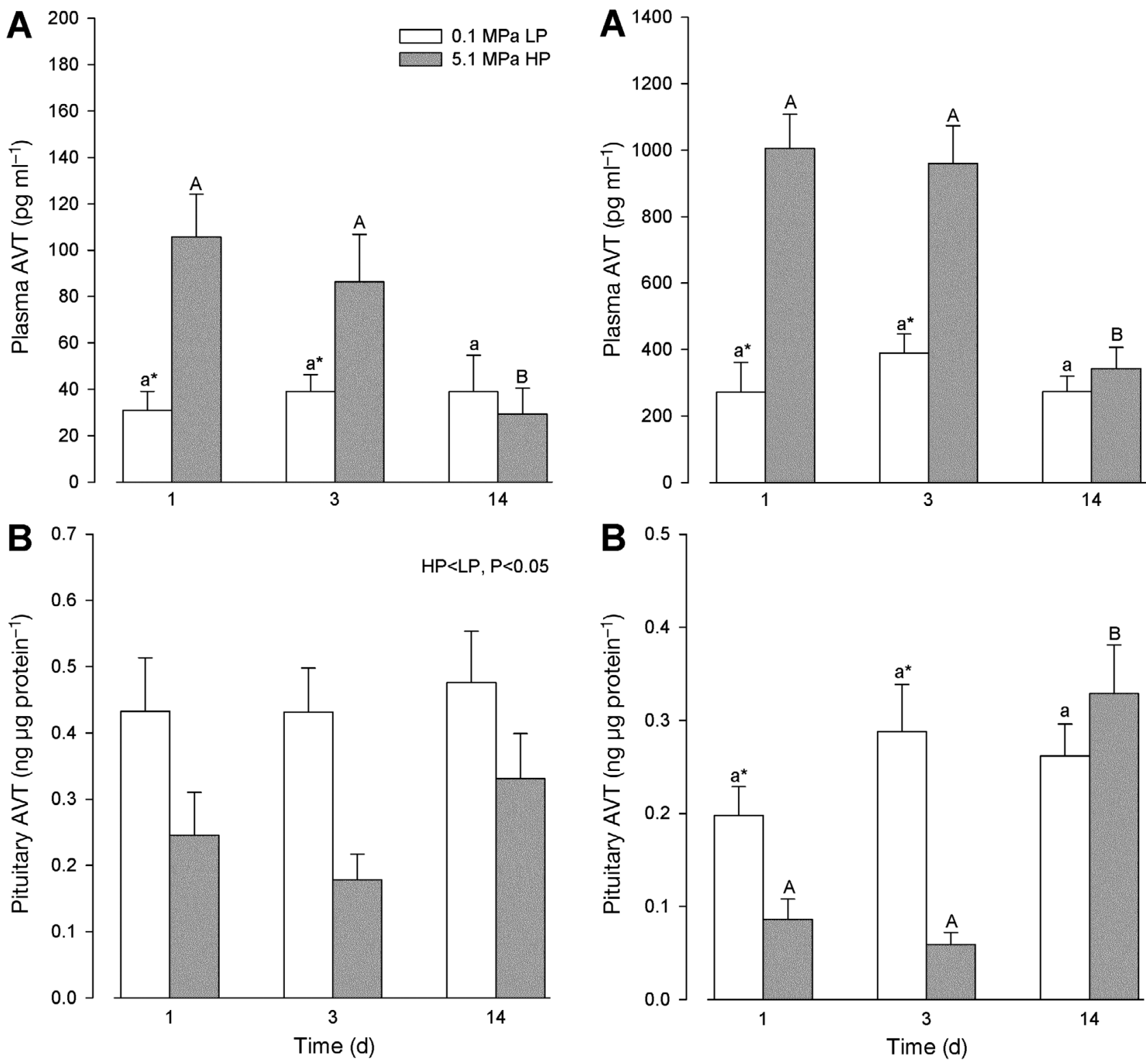

Fig. 1. (A) Arginine vasotocin (AVT) plasma and (B) pituitary levels in Oncorhynchus mykiss exposed for different times to 2 different hydrostatic pressure conditions. Results are presented as mean $\pm \mathrm{SE}, \mathrm{n}=6$ fish per group. Asterisk indicates significant differences between control groups (0.1 MPa) and high hydrostatic pressure groups (5.1 $\mathrm{MPa}$ ) inside the same sampling time, while different letters mean significant differences between groups inside the same pressure conditions at different times of exposure. LP: low pressure; HP: high pressure

freshwater (Table 1). Exposure to high hydrostatic pressure (5.1 MPa) for $1 \mathrm{~d}$ did not significantly affect the plasma concentrations of any of the monovalent ions measured in either fish species when they were compared to their respective control groups $(0.1 \mathrm{MPa})$. In trout, hydrostatic pressure did not alter plasma cortisol levels over a $7 \mathrm{~d}$ period (Table 2).

Fig. 2. (A) Arginine vasotocin (AVT) plasma and (B) pituitary levels in Scyliorhinus canicula exposed for different times to 2 different hydrostatic pressure conditions. Results are presented as mean $\pm \mathrm{SE}, \mathrm{n}=6$ fish per group. Asterisk indicates significant differences between control groups (0.1 MPa) and high hydrostatic pressure groups $(5.1 \mathrm{MPa})$ inside the same sampling time, while different letters mean significant differences between groups inside the same pressure conditions at different times of exposure. LP: low pressure; HP: high pressure

\section{DISCUSSION}

Our present study reveals for the first time that the fish vasotocinergic system is altered under high hydrostatic pressure conditions in 2 fish species with different osmoregulatory strategies and ecophysiological adaptations: the rainbow trout, a euryhaline 
teleost that can support a limited pressure range, and the dogfish, an osmoconforming chondrichthyan adapted to descend into deeper waters.

Circulating AVT levels quantified in our study in rainbow trout (control groups) were stable over the $2 \mathrm{wk}$ of the sampling period and ranged from $34.49 \pm$ 4.59 to $39.13 \pm 7.25 \mathrm{pg} \mathrm{ml}^{-1}$. Pituitary AVT content was also stable over time, with values ranging from $0.43 \pm 0.08$ to $0.48 \pm 0.08 \mathrm{ng} \mu$ protein $^{-1}$. It is also interesting that circulating AVT levels were significantly lower in trout used in this study than those reported previously (Rodríguez-Illamola et al. 2011) when juveniles of rainbow trout were sampled at a similar time of the day $\left(14: 00 h_{i} 100.93 \pm 13.98 \mathrm{pg}\right.$ $\mathrm{ml}^{-1}$ ). In contrast, AVT pituitary levels were similar in both studies. Since AVT analytical methods were HPLC-FD based in both experiments, and taking into account that trout were immature females (Rodríguez-Illamola et al. 2011), it can be assumed that the divergence found in the circulating AVT levels between these studies did not depend on the age and sex of the fish nor was it likely to have a methodological origin. However, seasonal rhythmic patterns could also affect the AVT production/release system in rainbow trout (Rodríguez-Illamola et al. 2011, So-

Table 1. Ion concentrations $(\mathrm{mM}$, mean $\pm \mathrm{SE})$ in plasma of rainbow trout Oncorhynchus mykiss and dogfish Scyliorhinus canicula under 2 different hydrostatic pressure conditions ( 0.1 and $5.1 \mathrm{MPa}$ ) for $1 \mathrm{~d}$. No significant differences were found between groups inside the same species. $\mathrm{n}=5$ per group. Data were analyzed by unpaired $t$-tests

\begin{tabular}{|lcccc|}
\hline Species & $\begin{array}{c}\text { Pressure } \\
(\mathrm{MPa})\end{array}$ & {$\left[\mathrm{Cl}^{-}\right]$} & {$\left[\mathrm{Na}^{+}\right]$} & {$\left[\mathrm{K}^{+}\right]$} \\
\hline O. mykiss & 0.1 & $122.5 \pm 2.9$ & $154.3 \pm 6.3$ & $3.7 \pm 0.4$ \\
& 5.1 & $128.0 \pm 1.1$ & $156.2 \pm 7.1$ & $3.1 \pm 0.5$ \\
S. canicula & 0.1 & $283.0 \pm 7.0$ & $286.5 \pm 8.9$ & $3.4 \pm 0.2$ \\
& 5.1 & $274.0 \pm 12.0$ & $249.5 \pm 16.4$ & $3.3 \pm 0.3$ \\
\hline
\end{tabular}

Table 2. Circulating cortisol levels (ng ml-1, mean $\pm \mathrm{SE}$ ) in rainbow trout Oncorhynchus mykiss under 2 different hydrostatic pressure conditions (0.1 and $5.1 \mathrm{MPa})$ at 1,3 and $7 \mathrm{~d}$ of exposure. No significant differences were found between groups. $\mathrm{n}=5$ per group. Data were analyzed by 2-way ANOVA

\begin{tabular}{|ccccc|}
\hline Species & $\begin{array}{r}\text { Pressure } \\
(\mathrm{MPa})\end{array}$ & Day 1 & Day 3 & Day 7 \\
\hline O. mykiss & 0.1 & $6.78 \pm 0.74$ & $8.06 \pm 1.24$ & $7.22 \pm 0.87$ \\
& 5.1 & $7.16 \pm 0.70$ & $10.70 \pm 1.45$ & $6.63 \pm 0.59$ \\
\hline
\end{tabular}

kołowska et al. 2020) and, therefore, the circulating AVT levels. Specifically, the lowest levels were found in the present study, which was conducted in December, while the highest basal circulating AVT levels were found in the previous study performed in April (Rodríguez-Illamola et al. 2011).

With respect to Scyliorhinus canicula, this is the first time in which circulating AVT levels were studied in this species, displaying values of 271 to $389 \mathrm{pg}$ $\mathrm{ml}^{-1}$ (Fig. 2A). Similar AVT levels were reported in the bull shark Carcharhinus leucas (148 to $238 \mathrm{fmol}$ $\mathrm{ml}^{-1}$; Anderson et al. 2006), while in the banded houndshark Triakis scyllium, the AVT levels found were lower $\left(87.7 \pm 13.2 \mathrm{fmol} \mathrm{ml}^{-1}\right.$; Hyodo et al. 2004). However, it is important to take into account that both studies used animals of a much younger age than those used in the present study. As far as we know this is the first time in which pituitary AVT levels were measured in a chondrichthyan species, showing mean values between $0.22 \pm 0.03$ and $0.29 \pm$ $0.05 \mathrm{ng} \mu$ protein $^{-1}$ (Fig. 2B). Therefore, it will be necessary to explore new situations and other species to know the characteristics of AVT production/ release in the different groups of chondrichthyans.

The main roles of AVT in fish are related to the antidiuretic function (Kulczykowska 1997, MartosSitcha et al. 2013), the response to stress conditions (Fryer \& Leung 1982, Gesto et al. 2014, MartosSitcha et al. 2019) and the behavioral and physiological regulation of reproduction (Foran \& Bass 1999, Bass \& Grober 2001, Sokołowska et al. 2015, Altmieme et al. 2019). We were able to confirm that hydrostatic pressure exposure per se does not elicit a stress response in trout since plasma cortisol levels were not elevated (Barton \& Iwama 1991). In elasmobranchs, the stress hormone $1 \alpha$-hydroxycorticosterone (Anderson 2012) was not measured in the present study, but we would assume a similar response in dogfish since experimental conditions were similar. Since previous studies reported alterations of the osmotic state in fish experiencing high hydrostatic pressure (Simon et al. 1989, Péqueux 2008), and taking into account the well-established role of AVT in ionosmotic regulation (Balment et al. 2006, Kulczykowska 2007), changes in AVT were expected in response to an osmotic challenge induced by high hydrostatic pressure in both studied species.

As an osmoconforming species (Hazon \& Henderson 1985), the dogfish kept at $34 \%$ presented higher blood concentrations of sodium, chloride and potassium in blood than trout in a hypoosmotic environment of $0.6 \%$ (Talas \& Gulhan 2013, Orun et al. 
2014). In both species, all these parameters kept similar values in high hydrostatic pressure compared to those in the hydrostatic pressure that corresponds to shallow water (control groups) at short term (1 d). In contrast to these results, previous studies in eels suggested that hydrostatic pressure produces a diuretic tendency in fish to increase circulating and tissue ion levels (sodium, chloride and magnesium in blood, and sodium and chloride in gills and muscle) after long-term exposure to high hydrostatic pressure (Simon et al. 1989). In the same way, Dunel-Erb et al. (1996) observed an increase in ionoregulatory cells in the gills of eels acclimated to high hydrostatic pressure.

AVT circulating levels increased during at least the first $3 \mathrm{~d}$ of exposure to high hydrostatic pressure $(5.1 \mathrm{MPa})$ in both species, and levels decreased to basal values at some point between 3 and $14 \mathrm{~d}$ of exposure to high-pressure conditions. Somero (1992) reported that cell membrane fluidity increases in fish exposed to high pressure for $15 \mathrm{~d}$, which reasonably could produce a diuretic trend at the level of the kidney. In our case, plasma monovalent ion concentrations in both fish species did not change in fish exposed at short term to high hydrostatic pressure $(5.1 \mathrm{MPa})$ in relation to those kept under low hydrostatic pressure $(0.1 \mathrm{MPa})$. So, the increased AVT release found in the present study could be an antidiuretic response that occurs under these conditions in a similar way to what happens after transferring fish to environments of increased salinity (Haruta et al. 1991, Balment et al. 1993, 2006, Kulczykowska 2007). As a consequence, our results suggest that increased plasma AVT levels could contribute to readjust plasma monovalent ion concentrations induced by high hydrostatic pressure, that seems to occur very efficiently in trout and in dogfish, at least in the short term.

The return to basal circulating AVT levels after long-term exposure of fish to high-pressure conditions (by $14 \mathrm{~d}$ ) suggests that other mechanisms could be involved in such an antidiuretic response, including probable increases of the AVT sensitivity in target tissues by means of increased AVT receptor expression. This has been demonstrated in fish acclimated to hyperosmotic water conditions (Lema 2010, Martos-Sitcha et al. 2014). This physiological state could help to maintain the antidiuretic AVT effects for longer periods, with lower costs for fish than maintaining high circulating AVT levels.

Concerning pituitary AVT content, it was initially ( 1 and 3 d) lower in dogfish exposed to the hydrostatic pressure of $5.1 \mathrm{MPa}$ in relation to the respective control groups, while it recovered to control values by $14 \mathrm{~d}$ of exposure. However, in trout, this pituitary AVT content fall to basal levels was independent of the period of exposure to high pressure. The evolution observed in the pituitary and the circulating AVT levels in dogfish kept under high hydrostatic pressure agree with the biphasic response observed in fish for this and other peptide hormones under altered salinity conditions (Perrott et al. 1991). Hence, stores of the neuropeptide are released into the blood during the initial exposure ( 1 to $3 \mathrm{~d}$ ), which is accompanied by an eventual drop in AVT content at the pituitary neuronal endings. Subsequently, AVT release into the blood decreases, allowing the pituitary to restore its AVT content to basal levels.

The effect of high hydrostatic pressure on circulating AVT levels was slightly higher in dogfish (an increase of 3.7 times at $1 \mathrm{~d}$ and 2.9 times at $3 \mathrm{~d}$ ) than in trout (2.4 times at $1 \mathrm{~d}$ and 2.2 times at $3 \mathrm{~d}$ ). This could be indicative of differences in the extension of the AVT response at the pituitary level in the 2 species studied. However, these data are still very preliminary and do not allow judgements at this level, especially considering that they are from 2 species with different osmoregulatory strategies and behaviors throughout the water column.

\section{CONCLUSIONS}

The present results point to a transient increase of pituitary AVT release in fish species exposed to high hydrostatic pressure, which is probably relevant for the maintenance of fluid and ion osmotic balance under these conditions. As we have used 2 species with very different physiological and osmoregulatory adaptations, it is not possible to make comparisons based on the differences observed in the response of AVT during exposure to high hydrostatic pressure, and so more in-depth studies are necessary.

Acknowledgements. This work was supported by Portuguese Foundation for Science and Technology grant PDTC/MAR/34016 to J.M.W. A.R.I. was supported by a postdoctoral fellowship from Xunta de Galicia, Axudas para Estadías en Centros de Investigación Fóra de Galicia (10.02.561A.480.1), in Portugal and now is supported by the projects CENAKVA (LM2018099) and Biodiversity (CZ.02.1.01./0.0/0.0/16_025/0007370) in the Czech Republic. The authors thank Dr. O. Gonçalves for assistance with fish maintenance and sampling during the experiment. 


\section{LITERATURE CITED}

Absil P, Papello M, Viglietti-Panzica C, Balthazart J, Panzica G (2002) The medial preoptic nucleus receives vasotocinergic inputs in male quail: a tract-tracing and immunocytochemical study. J Chem Neuroanat 24: 27-39

Acher R (1996) Molecular evolution of fish neurohypophysial hormones: neutral and selective evolutionary mechanisms. Gen Comp Endocrinol 102:157-172

Altmieme Z, Jubouri M, Touma K, Coté G, Fonseca M, Julian T, Mennigen JA (2019) A reproductive role for the nonapeptides vasotocin and isotocin in male zebrafish (Danio rerio). Comp Biochem Physiol B Biochem Mol Biol. 238:110333

Amer S, Brown JA (1995) Glomerular actions of arginine vasotocin in the in situ perfused trout kidney. Am J Physiol 269:R775-R780

Anderson WG (2012) The endocrinology of $1 \alpha$-hydroxycorticosterone in elasmobranch fish: a review. Comp Biochem Physiol A Mol Integr Physiol 162:73-80

Anderson WG, Pillans RD, Hyodo S, Tsukada T and others (2006) The effects of freshwater to seawater transfer on circulating levels of angiotensin II, C-type natriuretic peptide and arginine vasotocin in the euryhaline elasmobranch, Carcharhinus leucas. Gen Comp Endocrinol 147: 39-46

Balment RJ, Warne JM, Tierney M, Hazon N (1993) Arginine vasotocin and fish osmoregulation. Fish Physiol Biochem 11:189-194

Balment RJ, Lu W, Weybourne E, Warne JM (2006) Arginine vasotocin a key hormone in fish physiology and behaviour: a review with insights from mammalian models. Gen Comp Endocrinol 147:9-16

Barton BA, Iwama GK (1991) Physiological changes in fish from stress in aquaculture with emphasis on the response and effects of corticosteroids. Annu Rev Fish Dis $1: 3-26$

Bass AH, Grober MS (2001) Social and neural modulation of sexual plasticity in teleost fish. Brain Behav Evol 57: 293-300

Block BA, Dewar H, Blackwell SB, Williams TD and others (2001) Migratory movements, depth preferences, and thermal biology of Atlantic bluefin tuna. Science 293: 1310-1314

Carrera E, García T, Cespedes A, Gonzalez I, Sanz B, Hernyez PE, Martin R (1998) Identification of Atlantic salmon (Salmo salar) and rainbow trout (Oncorhynchus mykiss) by using polymerase chain reaction amplification and restriction analysis of the mitochondrial cytochrome b gene. J Food Prot 61:482-486

Chaube R, Singh RK, Joy KP (2015) Changes in vasotocin levels in relation to ovarian development in the catfish Heteropneustes fossilis exposed to altered photoperiod and temperature. Fish Physiol Biochem 41:1173-1186

Correia AT, Coimbra AM, Damasceno-Oliveira A (2012) Effect of the hydrostatic pressure on otolith growth of early juveniles of Nile tilapia Oreochromis niloticus. J Fish Biol 81:329-334

Damasceno-Oliveira A, Gonçalves J, Silva J, FernándezDurán B, Coimbra J (2004) A pressurising system for long-term study of marine or freshwater organisms enabling the simulation of cyclic vertical migrations. Sci Mar 68:615-619
Damasceno-Oliveira A, Fernández-Durán B, Gonçalves J, Couto E, Canário AV, Coimbra J (2012) Plasma steroid hormone levels in female flounder Platichthys flesus and the influence of fluctuating hydrostatic pressure. Comp Biochem Physiol A Mol Integr Physiol 163:272-277

*Duarte G, Segura-Noguera MM, Martín del Río MP, Mancera JM (2001) The hypothalamo-hypophyseal system of the white seabream Diplodus sargus: immunocytochemical identification of arginine-vasotocin, isotocin, melanin-concentrating hormone and corticotropinreleasing factor. Histochem J 33:569-578

* Dunel-Erb S, Sébert P, Chevalier C, Simon B, Barthélémy L (1996) Morphological changes induced by acclimation to high pressure in the gill epithelium of the freshwater yellow eel. J Fish Biol 48:1018-1022

FForan CM, Bass AH (1999) Preoptic GnRH and AVT: axes for sexual plasticity in teleost fish. Gen Comp Endocrinol 116:141-152

Fryer JN, Leung E (1982) Neurohypophysial hormonal control of cortisol secretion in the teleost Carassius auratus. Gen Comp Endocrinol 48:425-431

Gaither MR, Violi B, Gray HWI, Neat F and others (2016) Depth as a driver of evolution in the deep sea: insights from grenadiers (Gadiformes: Macrouridae) of the genus Coryphaenoides. Mol Phylogenet Evol 104:73-82

*Gesto M, Soengas JL, Rodríguez-Illamola A, Míguez JM (2014) Arginine vasotocin treatment induces a stress response and exerts a potent anorexigenic effect in rainbow trout, Oncorhynchus mykiss. J Neuroendocrinol 26: 89-99

Gibbs AG (1997) Biochemistry at depth. In: Randall DJ, Farrell AP (eds) Deep-sea fishes, Vol 16. Academic Press, London, p 239-278

Gillet MB, Suko JR, Santoso FO, Yancey PH (2001) Elevated levels of trimethylamine in muscles of deep-sea gadiform teleosts: a high pressure adaptation? J Exp Zool 279: 172-176

Günther A (1887) Descriptions of two new species of fishes from Mauritius. Proc Zool Soc Lond 55:550-551

* Haruta K, Yamashita T, Kawashima S (1991) Changes in arginine vasotocin content in the pituitary of the medaka (Oryzias latipes) during osmotic stress. Gen Comp Endocrinol 83:327-336

Hazon N, Henderson IW (1985) Factors affecting the secretory dynamics of 1 alpha-hydroxycorticosterone in the dogfish, Scyliorhinus canicula. Gen Comp Endocrinol 59: 50-55

*HHodo S, Tsukada T, Takei Y (2004) Neurohypophysial hormones of dogfish catshark, Triakis scyllium: structures and salinity-dependent secretion. Gen Comp Endocrinol 138:97-104

Kulczykowska E (1997) Response of circulating arginine vasotocin and isotocin to rapid osmotic challenge in rainbow trout. Comp Biochem Physiol A Mol Integr Physiol 118:773-778

Kulczykowska E (2007) Arginine vasotocin and isotocin: towards their role in fish osmoregulation. In: Baldisserotto B, Mancera JM, Kapoor BG (eds) Fish osmoregulation. Science Publishers, Enfield, NH, p 151-176

Kyne PM, Simpfendorfer CA (2010) Deepwater chondrichthyans. In: Carrier B, Musick JA, Heithaus MR (eds) Biology of sharks and their relatives II. CRC Press, Boca Raton, FL, p 37-113

Lema SC (2010) Identification of multiple vasotocin receptor cDNAs in teleost fish: sequences, phylogenetic analysis, 
sites of expression, and regulation in the hypothalamus and gill in response to hyperosmotic challenge. Mol Cell Endocrinol 321:215-230

Kema SC, Washburn EH, Crowley ME, Carvalho PG, Egelston JN, McCormick SD (2019) Evidence for a role of arginine vasotocin receptors in the gill during salinity acclimation by a euryhaline teleost fish. Am J Physiol Regul Integr Comp Physiol 316:R735-R750

* Mancera JM, Martínez-Rodríguez G, Skrzynska AK, Martos-Sitcha JA (2018) Osmoregulatory role of vasotocinergic and isotocinergic systems in the gilthead sea bream (Sparus aurata L). Gen Comp Endocrinol 257: $177-183$

Martos-Sitcha JA, Gregório SF, Carvalho ESM, Canario AVM and others (2013) AVT is involved in the regulation of ion transport in the intestine of the sea bream (Sparus aurata). Gen Comp Endocrinol 193:221-228

Martos-Sitcha JA, Fuentes J, Mancera JM, MartínezRodríguez G (2014) Variations in the expression of vasotocin and isotocin receptor genes in the gilthead sea bream Sparus aurata during different osmotic challenges. Gen Comp Endocrinol 197:5-17

* Martos-Sitcha JA, Cádiz L, Gozdowska M, Kulczykowska E, Martínez-Rodríguez G, Mancera JM (2019) Arginine vasotocin and cortisol co-regulate vasotocinergic, isotocinergic, stress, and thyroid pathways in the gilthead sea bream (Sparus aurata). Front Physiol 10:261

* Maruska KP, Mizobe MH, Tricas TC (2007) Sex and seasonal co-variation of arginine vasotocin (AVT) and gonadotropin-releasing hormone $(\mathrm{GnRH})$ neurons in the brain of the halfspotted goby. Comp Biochem Physiol A Mol Integr Physiol 147:129-144

McCormick SD, Bradshaw D (2006) Hormonal control of salt and water balance in vertebrates. Gen Comp Endocrinol $147: 3-8$

Forun ZI, Selamoglu Z, Gulhan MF, Erdogan K (2014) Role of propolis on biochemical and hematological parameters of Oncorhynchus mykiss exposed to cypermethrin. J Survey Fish Sci 1:21-35

Péqueux A (2008) Effects of high pressure on ion transport and osmoregulation. In: Ali MA (ed) Environmental physiology of fishes. Plenum, New York, NY, p 163-199

Perrott MN, Carrick S, Balment RJ (1991) Pituitary and plasma arginine vasotocin levels in teleost fish. Gen Comp Endocrinol 83:68-74

Priede IG (2017) Deep sea fishes: biology, diversity, ecology and fisheries. Cambridge University Press, Cambridge

Righton D, Westerberg H, Feunteun E, Økland F and others (2016) Empirical observations of the spawning migration of European eels: the long and dangerous road to the Sargasso Sea. Sci Adv 2:e1501694

Rodríguez-Illamola A， López-Patiño MA， Soengas JL, Ceinos RM, Míguez JM (2011) Diurnal rhythms in hypothalamic/pituitary AVT synthesis and secretion in rainbow trout: evidence for a circadian regulation. Gen Comp Endocrinol 170:541-549

Sangiao-Alvarellos S, Polakof S, Arjona FJ, Kleszczynska A and others (2006) Osmoregulatory and metabolic changes in the gilthead sea bream Sparus auratus after arginine vasotocin (AVT) treatment. Gen Comp Endocrinol 148:348-358

Editorial responsibility: Helmut Segner, Bern, Switzerland
Sébert P (2002) Fish at high pressure: a hundred-year history. Comp Biochem Physiol A Mol Integr Physiol 131: $575-585$

Sébert P, Theron M (2001) Why can the eel, unlike the trout, migrate under pressure. Mitochondrion 1:79-85

Sébert P, Pequeux A, Simon B, Barthelemy L (1991) Effects of long-term exposure to 101 ATA hydrostatic pressure on blood, gill and muscle composition and on some enzyme activities of the FW eel (Anguilla anguilla L.). Comp Biochem Physiol B Biochem Mol Biol 98:573-577

Sébert ME, Amerand A, Vettier A, Weltzien FA, Pasqualini C, Sébert P, Dufour S (2007) Effects of high hydrostatic pressure on the pituitary-gonad axis in the European eel, Anguilla anguilla (L.). Gen Comp Endocrinol 153:289-298

Simon B, Sébert P, Barthelemy L (1989) Effects of long-term exposure to hydrostatic pressure per se (101 ATA) on eel metabolism. Can J Physiol Pharmacol 67:1247-1251

Smith PK, Krohn RI, Hermanson GT, Mallia AK and others (1985) Measurement of protein using bicinchoninic acid. Anal Biochem 150:76-85

* Sokołowska E, Kleszczyńska A, Nietrzeba M, Kulczykowska E (2015) Annual changes in brain concentration of arginine vasotocin and isotocin correspond with phases of reproductive cycle in round goby, Neogobius melanostomus. Chronobiol Int 32:917-924

* Sokołowska E, Gozdowska M, Kulczykowska E (2020) Nonapeptides arginine vasotocin and isotocin in fishes: advantage of bioactive molecules measurement. Front Mar Sci 7:610

* Somero GN (1992) Adaptations to high hydrostatic pressure. Annu Rev Physiol 54:557-577

Talas S, Gulhan MF (2013) Effects of various pollen concentrations on some biochemical and hematological parameters and paraoxanase activity in rainbow trout (Oncorhynchus mykiss). Iran J Fish Sci 12:928-938

* Uchiyama M, Maejima S, Wong MK, Preyavichyapugdee N and others (2014) Changes in plasma angiotensin II, aldosterone, arginine vasotocin, corticosterone, and electrolyte concentrations during acclimation to dry condition and seawater in the crab-eating frog. Gen Comp Endocrinol 195:40-46

Vettier A, Labbe C, Amerand A, Da Costa G, Le Rumeur E, Moisan C, Sébert P (2006) Hydrostatic pressure effects on eel mitochondrial functioning and membrane fluidity. Undersea Hyperb Med 33:149-156

*Wearmouth VJ, Southall EJ, Morritt D, Sims DW (2013) Identifying reproductive events using archival tags: egglaying behavior of the small spotted catshark Scyliorhinus canicula. J Fish Biol 82:96-110

* Yancey PH, Siebenaller JF (2015) Co-evolution of proteins and solutions: protein adaptation versus cytoprotective micromolecules and their roles in marine organisms. J Exp Biol 218:1880-1896

* Yancey PH, Fyfe-Johnson AL, Kelly RH, Walker VP, Auñón MT (2001) Trimethylamine oxide counteracts effects of hydrostatic pressure on proteins of deep-sea teleosts. J Exp Zool 289:172-176

*Yancey PH, Gerringer ME, Drazen JC, Rowden AA, Jamieson A (2014) Marine fish may be biochemically constrained from inhabiting the deepest ocean depths. Proc Natl Acad Sci USA 111:4461-4465

Submitted: March 19, 2020; Accepted: August 17, 2020

Proofs received from author(s): November 25, 2020 